Article

\title{
Module-Based Product Configuration Decisions Considering Both Economical and Carbon Emission-Related Environmental Factors
}

\author{
Dong Yang ${ }^{1, *}$, Jia $\mathrm{Li}^{1, *}$, Bill Wang ${ }^{2}$ and Yong-ji Jia ${ }^{1}$ \\ 1 School of Business and Management, Donghua University, Shanghai 200051, China; yjjia@dhu.edu.cn \\ 2 Business Information Systems Department, Auckland University of Technology, \\ Auckland 1010, New Zealand; bill.wang@aut.ac.nz \\ * Correspondence: yangdong@dhu.edu.cn (D.Y.); jia.li@mail.dhu.edu.cn (J.L.)
}

Received: 14 January 2020; Accepted: 4 February 2020; Published: 5 February 2020

\begin{abstract}
With an increasing demand for green and environmentally friendly products, configuring a customized product from modular product design to satisfy both individualized customer requirements and environment restrictions has become a vital task for mass customization. In this paper, we addressed a module-based product configuration problem under carbon emission regulation, i.e., carbon cap-and-trade schema. The configuration problem under carbon cap-and-trade schema was formulated as a mixed-integer programming problem. Due to the NP-hard characteristics of the model, a genetic algorithm was employed to solve the configuration problems under carbon cap-and-trade. Experiments were carried out to analyze the effects of carbon emissions on product configuration decisions and carbon purchasing decisions. As a result, the range for carbon emission cap is suggested for both manufacturers and government agency, which provides the decision supporting for both customized and low-carbon production and green manufacturing.
\end{abstract}

Keywords: product configuration; mass customization; product family; sustainable manufacturing; carbon emission policy; genetic algorithm

\section{Introduction}

Product configuration is a means to implement customized products for customers by selecting modules combination from candidate modules, which is regarded as an enabling technology for mass customization [1]. In mass customization production, a product is designed as one consisting of various modules which implements different functions of products [2,3]. Furthermore, modules can be classified as common modules, variant modules and optional modules [4]. By selecting different module combinations, a product satisfying both customer individualized requirements and configuration rules can be derived. Product configuration has its root in the artificial intelligence domain in the early 1980s when the configuration system R1 was developed to configure a computer system using rule-based reasoning [5]. Since then, much attention has been paid to developing various methods for solving product configuration problems $[1,6]$. The main techniques include rule-based reasoning [5], case-based reasoning (CBR) [7,8] and the constraint satisfaction problem (CSP) [9-11]. Nevertheless, the above studies only concentrated on obtaining a feasible configuration and they did not consider how to seek an optimal configuration solution in case a numerous number of configurations exist. To handle the problem with optimal configuration, exact methods like mathematical programming [12] and meta-heuristic algorithms [13-15], such as particle swarm optimization (PSO) and genetic algorithm (GA), were utilized to determine the optimal or near-optimal configurations.

Recently, with an increasing concern for environmental issues as well as sustainable manufacturing, taking environmental factors such as carbon emissions into account during the product design and 
manufacturing stages has aroused great interests among researchers [16-18]. Firstly, the methods for measuring the GHG (Greenhouse Gas) emissions or carbon footprints of products during the manufacturing stage were investigated $[16,17,19]$. Furthermore, environmental impacts such as the reduction of $\mathrm{CO}_{2}$ emissions are frequently addressed in remanufacturing [20,21], sustainable product design [22], product recycling and circularity [23,24]. However, the studies do not deal with products with a modular design as well as corresponding modular-based product configuration. Only a limited number of studies have been conducted to explore the product configuration problem with environmental consideration [25,26]. For example, Tang et al. (2017) built a bi-objective optimization model with simultaneous consideration of customer satisfaction and the environmental impacts in product configuration [25]. The environmental impacts in their study were addressed by considering $\mathrm{CO}_{2}$ emissions in the product configuration process. Nevertheless, their study on product configuration only considered environmental impacts as an optimization objective to reduce carbon emissions. Enforcing environmental regulations from international environmental organizations such as carbon cap-and-trade regulation are not taken into account in their study.

To overcome the effect of global warming on climate change, the United Nations Framework Convention on Climate Change (UNFCCC) and the Kyoto Protocol were set forward to reduce GHG emissions around the world [27]. Different types of emission regulation schemes have been suggested by UNCFC and the Kyoto Protocol to curb GHG emissions. The carbon tax and carbon cap-and-trade are the two main carbon regulations applied in practices [28]. For carbon tax, an addition tax is paid for a certain amount of carbon emissions. For the cap-and-trade regulation, governments allocate a certain amount of permitted carbon allowances to companies. To meet the pre-determined carbon allowances, i.e., carbon cap, companies can either reduce their carbon emissions or buy extra carbon permits to increase their allowances via carbon trading markets. Therefore, it is imperative for the manufacturers with mass customization paradigm to investigate the effects of carbon regulations on product configuration results. In this study, we mainly addressed the product configuration problem under carbon cap-and-trade regulation. Our contributions are two-folds. Firstly, the previous studies on remanufacturing set a target for carbon emission reduction when environmental impacts are examined. Although the product configuration research carried out by tang et al. (2017) addressed environmental impacts [25], which is very close to our study, it aims to reduce the amount of $\mathrm{CO}_{2}$ emissions. Therefore, the aforementioned studies do not deal with the carbon emission regulation like cap-and-trade. Secondly, the effects of permitted carbon allowances on configuration results and various costs including module cost and carbon purchase cost were analyzed and a reasonable range for setting carbon allowances is suggested for decision makers.

The paper is organized as follows. Section 2 reviews the related work. In Section 3, the product configuration problem under carbon emission restrictions is described and a mixed-integer programming model is built. Section 4 addresses the solution algorithm, i.e., genetic algorithm, for solving the optimization model for product configuration. A case study on a configurable ranger-drilling machine was used to illustrate the effectiveness of the presented model and the corresponding solution algorithm, as described in Section 5. Finally, the effect of carbon emissions on product configuration is analyzed. Section 6 summarizes conclusions and future research directions.

\section{Literature Review}

This study is related to both product configuration problems and environmental impacts in product design and manufacturing. Below, we firstly addressed the related work regarding product configuration problems. Then, the literature about environmental impacts in product design and manufacturing are elaborated.

\subsection{Product Configuration}

Much efforts have been made to develop methods for solving product configuration problems. The methods, including rule-based reasoning, case-based reasoning (CBR) and constraint satisfaction 
problem (CSP), aim to find a feasible configuration, given the configuration rules and customer requirements. For example, Tseng and Lee applied the CBR to obtain a feasible configuration by considering the similarity between the previous configuration cases and the current configuration requirements $[7,8]$. However, the hierarchical structures of products are ignored in the CBR and thus, it cannot deal with product configuration with structured components. CSP, as a descriptive representation independently of concrete domain knowledge, has become the mainstream method for solving product configuration problems [9-11]. For instance, Stumptner and Aldanondo employed CSP to inference a valid configuration by transforming configuration concepts such as attributes, module, and rules into the elements like variables and domains in the CSP $[9,11]$. Nevertheless, the above studies only concentrated on obtaining a feasible configuration and they did not consider how to find an optimal configuration solution in the case of the existence of numerous configurations. To handle the problem with optimal configuration, exact methods like mathematical programming [12], and meta-heuristic algorithms [13-15] such genetic algorithm (GA) are utilized to determine the optimal or near-optimal configurations. For example, Aldanondo and Vareilles constructed an integer linear programming model for optimizing the product configuration problem and deriving the optimal configuration [12]. Hong et al. employed GA for identifying optimal product configuration given the AND-OR tree representation for a product family and customer requirements [13]. With great achievement in solving algorithms for product configuration, some recent studies have begun to concentrate on eliciting customer preferences by using the fuzzy kano model [29], concurrent product configuration and process configuration [30], utilizing online review data to obtain feasible configuration [31] and design a product configuration system based on the adaptable open architecture product platform [32].

\subsection{Environmental Considerations in Product Design and Remanufacturing}

Environmental impacts, especially $\mathrm{CO}_{2}$ emissions, are gradually recognized in product design, manufacturing and remanufacturing. To start with, some researchers focus on developing quantitative methods for measuring GHG emissions of products during the product design and manufacturing stages. For example, Song and Lee presented an approach to estimating the GHG (Greenhouse Gas) emission of a product through its life cycle including raw material, manufacturing, transportation, distribution, and use [16]. Zhang et al. developed a new way of calculating carbon footprint of a product by focusing on the connection characteristics between components [17]. Yi et al. investigated the potential of process parameter optimization to minimize carbon emissions during machine processing for low-carbon manufacturing [19]. Furthermore, reducing environmental impacts is mainly dealt with in remanufacturing. For example, Kim and Kwak presented a green-profit model for a line of new and remanufactured products where a target for environmental-impact savings is set [20]. Based on the work, Saidani et al. further extended the green-profit model for new and remanufactured products by considering the product circularity performance [23]. Igarashi et al. proposed a multi-criteria optimization model for end-of-life product disassembly systems, taking $\mathrm{CO}_{2}$ saving rates, recycling and cost into account [24]. Loon and Wassenhove developed a simper tool for a supplier to assess the economic and environmental impact of remanufacturing [21].

Only a few studies regarding product family and product configuration considered the environmental impacts. Kwak and Kim developed an optimization model for a product family design from an end-of-life perspective and the environmental impacts, i.e., the recovery rate of materials, were considered in the model [26]. Work closely related to our study was reported by Tang et al. (2017) [25], which addressed product configuration problems with the objective of reducing carbon emissions. However, they do not deal with the carbon emission regulations proposed by (UNFCCC) and the Kyoto Protocol, among which carbon cap-and-trade and carbon tax are the two main types of regulations applied. Therefore, our main contribution was to investigate the product configuration problem under carbon cap-and-trade regulation and analyze the effect of this regulation on configuration results. 


\section{Product Configuration Problem under Carbon Emission Restrictions}

\subsection{Problem Statement}

It is assumed that a company which implements mass customization production offers customers with customized products by employing module-based product design. Namely, the product consists of various modules with different functions. A module is composed of module instances with the same or similar functions, but somewhat different attributes or performances of products. The module instances belonging to the same module are exclusively selected when configuring a product, namely that the module instances are exclusive-OR (XOR). Furthermore, there exist configuration rules between module instances due to economical, technical and lawful restrictions. Typical configuration rules include selective rules and incompatible rules. For the former, it represents that the selection of a module instance must select another module instance in the same configuration because they are dependent. For the latter, it means that two instances are incompatible and thus, they cannot exist in the same configuration. By selecting candidate instances, an individualized product satisfying customers' requirements can be derived.

With the increasing concern for environmental issues, the company decides to pay equal importance to both individualized requirements for customers and carbon emission policies. Thus, the carbon emission regulations, such as carbon-cap, carbon-tax and carbon cap-and-trade, must be observed when a customized product is configured. The carbon-cap schema enforces that the amount of carbon emissions cannot exceed the specified quota. For the cap-and-trade regulation, an additional amount of carbon emissions can be purchased (or sold) via a carbon exchange market when the carbon emission amount is below (or beyond) the quota. Compared to carbon-cap, cap-and-trade is more flexible for a manufacturer and thus, the cap-and-trade schema is adopted was this study. Therefore, the product configuration problem under carbon emission regulation was defined to select candidate module instances to constitute a valid product such that configuration rules and the cap-and-trade regulation are observed and customer requirements are met.

\subsection{Mathematical Model}

The product configuration problem under the carbon cap-and-trading schema can be formulated as a mixed-integer programming model. The objective of the model was to determine the selection of module instances for customized products with the objective of minimizing total configuration costs including module cost and possibly carbon purchase cost. In particular, the decision variables in the optimization model include binary variables $x_{i j k}$, representing whether module instance $k$ of module $j$ for customer $i$ is selected in the configuration $(=0)$ or not $(=1)$, and continuous variables $E_{b}$, meaning the possible amount of purchased carbon emissions.

The notations for sets, variables and parameters are shown as follows.

(1) Index

$i, i^{\prime}(=1,2, \cdots, N):$ Index for customer orders.

$j, j^{\prime}(=1,2, \cdots, M):$ Index for modules.

$k, k^{\prime}(=1,2, \cdots, K):$ Index for module instances.

(2) Set and Parameters

$c_{j k}$ : Assembly cost for module instance $k$ of module $j$.

$d_{i}$ : Size of customer order $i$.

$c_{e}$ : Price for carbon emission exchange.

$E_{p}$ : Total amount of produced carbon emission for configured products.

$E_{q}$ : Carbon quota for the company. 
$\varepsilon_{j k}$ : Per-unit amount of carbon emissions for instance $k$ of module $j$ during the assembly processes.

$\alpha$ : Penalty factor for purchasing carbon emissions.

$C R_{i}$ : Requirements of customer order $i$ for module instances.

XOR: Set for candidate module instances of a module.

SEL: Set for module instances with selective rules.

INC: Set for module instances with incompatible rules.

(3) Variables

$x_{i j k}$ : Module instance $k$ of module $j$ for customer $i$ is selected in the configuration $(=0)$ or not $(=1)$.

$E_{b}$ : Amount of purchased carbon emissions.

With the notations in mind, the mathematical programming model for product configuration under carbon cap-and-trading schema is constructed below.

$$
\min f=\sum_{i=1}^{N} \sum_{j=1}^{M} \sum_{k=1}^{K} d_{i} c_{j k} x_{i j k}+\alpha c_{e}\left(E_{b}, 0\right)^{+}
$$

s.t

$$
\begin{gathered}
\sum_{k=1}^{K} x_{i j k}=1 \quad \forall(i, j) \in X O R \\
x_{i j k}+x_{i j^{\prime} k^{\prime}} \leq 1 \quad \forall\left(k, k^{\prime}\right) \in I N C \\
x_{i j k} \leq x_{i j^{\prime} k^{\prime}} \quad \forall\left(k, k^{\prime}\right) \in S E L \\
x_{i j k}=C R_{i} \forall i \forall j \forall k \\
E_{p}=\sum_{i=1}^{N} \sum_{j=1}^{M} \sum_{k=1}^{K} \varepsilon_{j k} d_{i} x_{i j k} \\
E_{b}=E_{p}-E_{q} \\
E_{b} \geq 0 \\
x_{i j k}=0,1 \forall i \forall j \forall k
\end{gathered}
$$

The objective function (1) minimizes the total module costs and the costs for purchasing carbon emissions. Here, the term $\left(E_{b}, 0\right)^{+}$means $\max \left(0, E_{b}\right)$ and $\alpha$ is a penalty factor with the aim of avoiding purchasing a too high level of carbon emissions from the market. Constraints (2) ensure XOR structure restrictions among candidate module instances of a module, namely that only an instance of a module can be selected. Constraints (3) enforce the incompatible rules where two module instances cannot be selected in the same configuration. Constraints (4) guarantee the selective rules where the existence of a module instance depends on that of another module instance. Customer requirements are specified on the requirement for the existence of module instances by mapping functional requirements of a product into its modules, as enforced by Constraints (5). Equation (6) calculates the total amount of carbon emissions for a product during the configuration processes. The possible carbon purchase amount is inferred by Equation (7). Constraints (8) and (9) restrict decision variables.

\section{Propose Algorithm}

The configuration optimization model mentioned above is a combinational optimization problem and thus, is an NP-hard one. As a consequence, it is very difficult to solve this by classical mathematical programming methods, especially considering the large-sized problem. The meta-heuristic algorithm is more effective than the traditional methods. Many heuristic algorithms, such as the genetic algorithm 
and the particle swarm algorithm, have been proposed to solve the combinational optimization problem. Owing to its simple computation and robust search ability, the genetic algorithm was adopted in this paper to solve the product configuration model under the carbon cap-and-trading schema in Section 2. The evolutionary mechanisms, including encoding, crossover and mutation operators in the genetic algorithm for solving the product configuration model are elaborated below.

\subsection{Encoding}

A solution to the product configuration problem is denoted by a chromosome. The integer-coding approach was employed in this study to represent a chromosome. The locus of a gene determines the modules and the value of the gene represents the module instance of the module, i.e., the decision variable $x_{i j k}$. Therefore, the range of the value of a gene is $\left[1, K_{j}\right]$ where $K_{j}$ is the number of instances of module $j$. An example of a chromosome for product configuration problem is shown in Figure 1. It indicates that seven modules are contained in a product. For module 1, the second module instance is selected in the configuration and for module 2, the first module instance selected. For module 3, the second instance is selected and for module 4 , the third selected, etc.

\begin{tabular}{|c|c|c|c|c|c|}
\hline Module & 1 & 2 & 3 & 4 & 5 \\
\hline$x$ & 2 & 1 & 2 & 3 & 2 \\
\hline
\end{tabular}

Figure 1. An example of a chromosome.

\subsection{Selection and Crossover Operator}

By the selection operator, the parent chromosomes are selected to reproduce offspring. The tournament selection was utilized in this study to pick up a certain number of individuals and then select the best one into a set until the needed number of individuals in the set is met. For the crossover operator, the uniform crossover, where each gene in the child chromosome comes from two parents in the equal probability, is exploited to produce child chromosomes. For example, as shown in Figure 2, for parent 1 and parent 2, each gene in the chromosomes is copied from parent 1 or parent 2 in equal probability. Due to the fact that both third genes in both parents are the value 2 , the value of the third gene in the child chromosome stays the same, i.e., value 2 . The child chromosome in the figure denotes that for modules 1, 2, 3 and 5, the second instances from the corresponding parents were selected in the configuration and for module 4 , the first instance from parent 2 was selected.

Parent chromosome 1

Parent chromosome 2

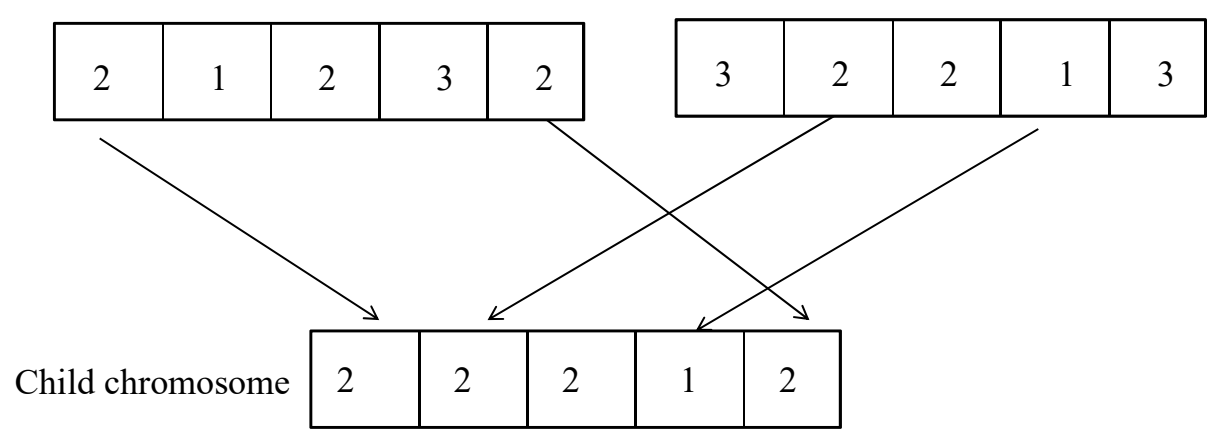

Figure 2. Crossover operator for product configuration.

\subsection{Mutation Operator}

By using the mutation operator, the genetic algorithm can be prevented to be trapped in local optimum. The conventional single-point mutation is adopted in this study to mutate a gene in a chromosome. An example of a mutation operation for the product configuration problem is 
illustrated in Figure 3. For example, the value of the third gene is changed from value 2 to 3 after the mutation operation is carried out. This means that for module 3 , the second instance is selected in the configuration before mutation and then the third module instance is selected after mutation.

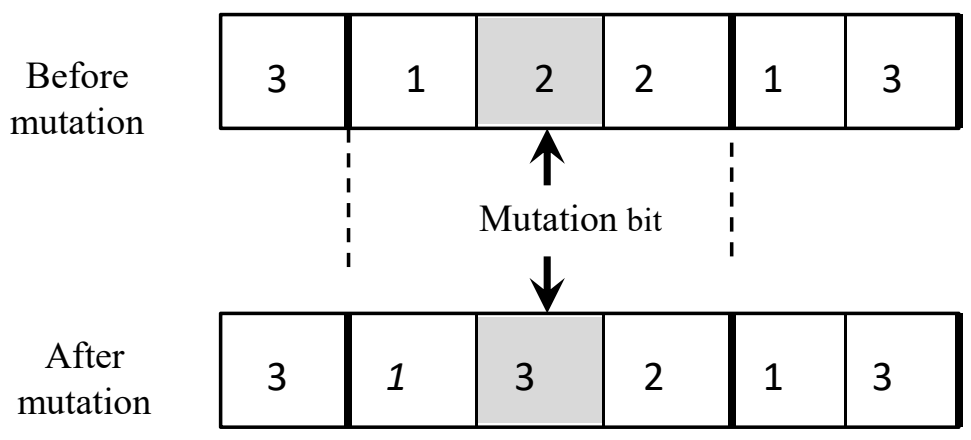

Figure 3. Mutation operation for product configuration.

\subsection{Constraint Handling}

As described in Section 2.2, Constraints (1)-(9) are contained in the optimization model for product configuration. However, the chromosomes reproduced by crossover and mutation operators might not satisfy all the constraints (1)-(9). As a result, constraint violation might occur and thus, must be handled in the evolutionary processes of the genetic algorithm. There exist two types of constraint handling approaches in GA [33]. One is the repair approach where the violated chromosome is transformed to a feasible one according to the repair rules or algorithms. The other is the penalty approach where a penalty term is added to the objective function to avoid invalid chromosomes entering into next-generation population. The penalty approach is employed in this study due to its simplicity and easy to implementation. Based on the penalty approach, the objective function (1) in Section 2 is modified as below.

$$
f^{\prime(x)}=\left\{\begin{array}{c}
0 \text { all constraints satisfied } \\
f(x)+\theta\left(\sum_{h=1}^{H}\left(l_{h}(x)-r_{h}(x)\right)+\sum_{s=1}^{S}\left|q l_{s}(x)-q r_{s}(x)\right|\right) \text { otherwise }
\end{array}\right.
$$

Here, $\theta$ is a penalty coefficient. $l_{h}(x)$ denotes the left-hand expression of the inequality constraints with the form ' $\leq$ ' whereas $r_{h}(x)$ is the right-hand expression of the inequality constraint with the form ' $\leq$ '. $H$ is the number of the set that contain all invalid inequalities. Similarly, $q l_{s}(x)$ represents the left-hand expression of the invalid equality constraint while $\mathrm{qr}_{\mathrm{s}}(\mathrm{x})$ is the the right-hand expression of the invalid equality. $S$ is the number of the invalid equality set.

\subsection{Fitness and Population Initialization}

The fitness of a chromosome determines the chance of its survival in next generation evolution. Greater fitness value can ensure the large probability of being selected in the next generation evolution of a population. Owing to the objective function $f(x)$ in the product configuration problem as a minimization one, the fitness of a chromosome in the genetic algorithm for solving the configuration problem is defined as $-f(x)$. Initial population is obtained by randomly generating a group of feasible chromosomes that satisfy all constraints specified in the product configuration model, i.e., Constraints (2)-(9). Moreover, the elite retention strategy where the chromosome with best fitness value, i.e., the best chromosome is kept in next-generation population is employed in the genetic algorithm such that the quality of the population can be enhanced. The flowchart of the employed genetic algorithm for solving product configuration problem is depicted in Figure 4. As shown in the figure, the algorithm begins with the initialization of some parameters, such as the size of population $n P o p$, the maximal number of iteration $T$, the probabilities of mutation and crossover operation. Then, the initial population 
is randomly generated and the fitness values of chromosomes in the population are evaluated. The tournament selection operator is utilized to select the parents and the uniform crossover operator is used to reproduce offspring in the next-generation population. The reproduced offspring are mutated in some probability according to the single-point mutation operation. If the mutated chromosomes violate the constraints specified in the product configuration model, the penalty-based approach is utilized to add a penalty term into the objective function, as described in Section 4.4. Otherwise, the fitness values of the population are calculated and the chromosomes in population are ranked according to their fitness value in a decreasing order. The chromosomes ranked in top $n$ Pop constitute the next-generation population and thus in this way the elite is reserved. The above processes are repeated until the number of iteration exceeds the specified maximal number of iteration. At that time, the optimal configuration result and the amount of carbon emissions to be purchased are derived.

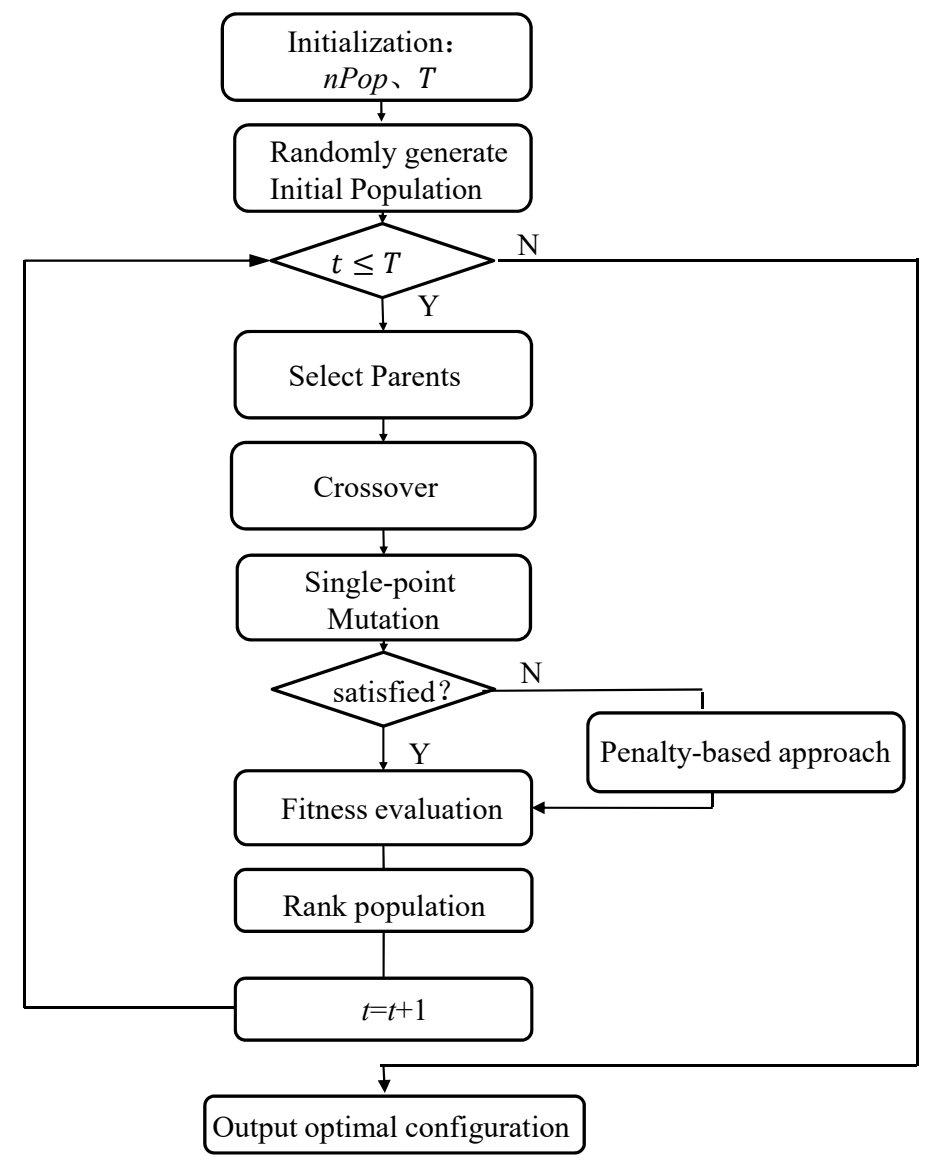

Figure 4. Genetic algorithm for product configuration.

\section{Case Study}

\subsection{Case Data}

A ranger-drilling machine manufacturer offers a configurable product family for customers since the ranger-drilling machines is often used for digging tunnels, mining and excavating rivers and the structure of products highly depends on their working environment. The ranger-drilling machine is planned into a modular structure which contains eleven modules. The eleven modules are as follows: engine module $\left(\mathrm{M}_{1}\right)$, tank module $\left(\mathrm{M}_{2}\right)$, air conditioner module $\left(\mathrm{M}_{3}\right)$, Extra Fuel pump module $\left(\mathrm{M}_{4}\right)$, Suction head module $\left(\mathrm{M}_{5}\right)$, Rock driller module $\left(\mathrm{M}_{6}\right)$, Drilling attachment module $\left(\mathrm{M}_{7}\right)$, boom module $\left(\mathrm{M}_{8}\right)$, Shovel module $\left(\mathrm{M}_{9}\right)$, Track module $\left(\mathrm{M}_{10}\right)$, and winch module $\left(\mathrm{M}_{11}\right)$. Each module contains several module instances (components), which have the same or similar functions and differ in the performances or characteristic of products. The information about modules and corresponding 
module instances for a ranger-drilling machine is shown in Table 1. The amount of carbon emissions for a module instance in product assembly is calculated via the activity-based method mentioned in [18], considering only the carbon emission caused by electricity. The carbon emission coefficient per-unit electricity in China is $0.6574 \mathrm{~kg} \mathrm{CO}_{2} \mathrm{e} / \mathrm{kwh}$, and the price of carbon emission in Shanghai Environment and Energy Market is averagely 5.71 dollars/ton. The configuration rules between module instances and the carbon emission limitation, i.e., carbon cap, are shown in Table 2. As shown in the table, the limitation for carbon emission amount. i.e., carbon cap, by a product is $74 \mathrm{~kg} \mathrm{CO}_{2} \mathrm{e}$. The configuration requirements for a customer are shown in Table 3 and the number of ordered product is 100 .

Table 1. Modules and module instances for a ranger-drilling product family.

\begin{tabular}{cccc}
\hline Module & Module Instance & $\begin{array}{c}\text { Cost } \\
\text { (dollars) }\end{array}$ & $\begin{array}{c}\text { Carbon Emission } \\
\left.\text { (kg CO } \mathbf{C}_{2} \mathbf{e}\right)\end{array}$ \\
\hline \multirow{2}{*}{$\mathrm{M}_{1}$} & $\mathrm{M}_{11}$ & 80 & 3.18 \\
& $\mathrm{M}_{12}$ & 70 & 9.75 \\
$\mathrm{M}_{2}$ & $\mathrm{M}_{21}$ & 110 & 4.12 \\
& $\mathrm{M}_{22}$ & 125 & 6.83 \\
$\mathrm{M}_{3}$ & $\mathrm{M}_{31}$ & 140 & 8.43 \\
& $\mathrm{M}_{32}$ & 164 & 6.34 \\
$\mathrm{M}_{4}$ & $\mathrm{M}_{33}$ & 176 & 11.75 \\
& $\mathrm{M}_{41}$ & 56 & 3.23 \\
$\mathrm{M}_{5}$ & $\mathrm{M}_{42}$ & 45 & 4.87 \\
& $\mathrm{M}_{51}$ & 230 & 10.67 \\
& $\mathrm{M}_{52}$ & 225 & 6.98 \\
$\mathrm{M}_{6}$ & $\mathrm{M}_{53}$ & 198 & 9.56 \\
& $\mathrm{M}_{61}$ & 123 & 10.23 \\
$\mathrm{M}_{7}$ & $\mathrm{M}_{62}$ & 134 & 6.84 \\
& $\mathrm{M}_{63}$ & 158 & 14.10 \\
$\mathrm{M}_{8}$ & $\mathrm{M}_{71}$ & 250 & 3.89 \\
& $\mathrm{M}_{72}$ & 240 & 4.50 \\
$\mathrm{M}_{9}$ & $\mathrm{M}_{81}$ & 20 & 0.9 \\
& $\mathrm{M}_{82}$ & 25 & 0.7 \\
$\mathrm{M}_{10}$ & $\mathrm{M}_{91}$ & 76 & 6.30 \\
& $\mathrm{M}_{92}$ & 70 & 11.70 \\
$\mathrm{M}_{11}$ & $\mathrm{M}_{93}$ & 60 & 13.87 \\
& $\mathrm{M}_{10,1}$ & 12 & 0.5 \\
& $\mathrm{M}_{10,2}$ & 10 & 5.56 \\
& $\mathrm{M}_{11,1}$ & 28 & 8.57 \\
\hline
\end{tabular}

Table 2. Configuration rules and carbon cap.

\begin{tabular}{|c|c|c|c|}
\hline Configuration Rule & Rule Type & Module Instances & Meaning \\
\hline 1 & Selective rule & $\mathrm{M}_{22}, \mathrm{M}_{33}$ & $\begin{array}{l}\text { The Selection of } \mathrm{M}_{22} \text { requires the selection } \\
\text { of } \mathrm{M}_{33} \text { in the same configuration }\end{array}$ \\
\hline 2 & Selective rule & $\mathrm{M}_{33}, \mathrm{M}_{53}$ & $\begin{array}{l}\text { The Selection of } \mathrm{M}_{33} \text { requires the selection } \\
\text { of } \mathrm{M}_{53} \text { in the same configuration }\end{array}$ \\
\hline 3 & Selective rule & $\mathrm{M}_{11,1}, \mathrm{M}_{63}$ & $\begin{array}{l}\text { The Selection of } \mathrm{M}_{11,1} \text { requires the selection } \\
\text { of } \mathrm{M}_{63} \text { in the same configuration }\end{array}$ \\
\hline 4 & Incompatible rule & $\mathrm{M}_{93}, \mathrm{M}_{61}$ & $\begin{array}{l}\mathrm{M}_{93} \text { and } \mathrm{M}_{61} \text { cannot exist in the } \\
\text { same configuration }\end{array}$ \\
\hline 5 & Equal rule & $\mathrm{M}_{4}, \mathrm{M}_{8}$ & $\begin{array}{c}\mathrm{M}_{4} \text { and } \mathrm{M}_{8} \text { must be selected the same } \\
\text { instance number. }\end{array}$ \\
\hline 6 & Carbon cap & & $\begin{array}{l}\text { Carbon emission amount for a product is } \\
\text { smaller or equal to } 74 \mathrm{kgCO}_{2}\end{array}$ \\
\hline
\end{tabular}


Table 3. Customer requirements.

\begin{tabular}{cc}
\hline Configuration Requirement & Explanation \\
\hline 1 & The customer requires $\mathrm{M}_{21}$ in the product. \\
2 & The customer requires $\mathrm{M}_{11,2}$ in the product. \\
\hline
\end{tabular}

\subsection{Configuration Results}

The genetic algorithm for solving product configuration model in Section 3 is programmed in Matlab 2014b and the parameter setting for the algorithm is as follows. The crossover probability is 0.8 , the crossover probability 0.2 , the population size 25 , and the number of maximal iterations is 50 . The optimal configuration results and the optimal amount of purchased carbon amount when carbon cap is $74 \mathrm{~kg} \mathrm{CO}_{2} \mathrm{e}, 50.85 \mathrm{~kg} \mathrm{CO}_{2} \mathrm{e}, 40 \mathrm{~kg} \mathrm{CO}_{2} \mathrm{e}$, respectively, are shown in Table 4. It can be seen that the module instances with relatively low cost but high GHG emissions tends to be selected when carbon emission limitation is loose, namely that carbon cap is $74 \mathrm{~kg} \mathrm{CO}_{2} \mathrm{e}$. As a consequence, the configured product has low total cost and rather high GHG emissions. On the other hand, it tends to select the module instances with relatively high cost, but low GHG emission when carbon restriction is strict, for example when carbon cap is 50.85 or $40 \mathrm{~kg} \mathrm{CO}_{2} \mathrm{e}$. Therefore, the configured product is of high cost but low carbon emissions.

Table 4. Optimal configuration results.

\begin{tabular}{|c|c|c|c|}
\hline Carbon Cap & $\begin{array}{c}40 \\
\mathrm{~kg} \mathrm{CO}_{2} \mathrm{e}\end{array}$ & $50.85 \mathrm{~kg} \mathrm{CO}_{2} \mathrm{e}$ & $\begin{array}{c}74 \\
\mathrm{~kg} \mathrm{CO} \\
2 \mathrm{e}\end{array}$ \\
\hline \multirow{12}{*}{$\begin{array}{l}\text { Optimal } \\
\text { configuration } \\
\text { result }\end{array}$} & Module instances & Module instances & Module instances \\
\hline & $\mathrm{M}_{11}$ & $\mathrm{M}_{11}$ & $\mathrm{M}_{12}$ \\
\hline & $\mathrm{M}_{21}$ & $\mathrm{M}_{21}$ & $\mathrm{M}_{21}$ \\
\hline & $\mathrm{M}_{32}$ & $\mathrm{M}_{32}$ & $\mathrm{M}_{31}$ \\
\hline & $\mathrm{M}_{41}$ & $\mathrm{M}_{41}$ & $\mathrm{M}_{42}$ \\
\hline & $\mathrm{M}_{52}$ & $\mathrm{M}_{52}$ & $\mathrm{M}_{53}$ \\
\hline & $\mathrm{M}_{62}$ & $\mathrm{M}_{62}$ & $\mathrm{M}_{61}$ \\
\hline & $\mathrm{M}_{71}$ & $\mathrm{M}_{71}$ & $\mathrm{M}_{72}$ \\
\hline & $\mathrm{M}_{82}$ & $\mathrm{M}_{81}$ & $\mathrm{M}_{81}$ \\
\hline & $\mathrm{M}_{91}$ & $\mathrm{M}_{91}$ & $\mathrm{M}_{92}$ \\
\hline & $\mathrm{M}_{10,1}$ & $\mathrm{M}_{10,1}$ & $\mathrm{M}_{10,2}$ \\
\hline & $\mathrm{M}_{11,2}$ & $\mathrm{M}_{11,2}$ & $\mathrm{M}_{11,2}$ \\
\hline Total cost (dollars) & 1589 & 1158 & 1048 \\
\hline Module cost (dollars) & 1163 & 1158 & 1048 \\
\hline Purchase cost for extra carbon amount (dollars) & 426 & 0 & 0 \\
\hline Carbon emission amount $\left(\mathrm{kg} \mathrm{CO}_{2} \mathrm{e}\right)$ & 50.65 & 50.85 & 73.53 \\
\hline Purchased (or excessive)carbon amount $\left(\mathrm{kg} \mathrm{CO}_{2} \mathrm{e}\right)$ & 10.65 & 0 & -0.47 \\
\hline
\end{tabular}

\subsection{Parameter Analysis}

The effects of carbon cap on total configuration costs, module costs, and purchase costs for carbon emissions are further analyzed in this study. Figure 5 shows the change of total configuration costs, module costs, and purchased cost with carbon cap. Obviously, all three kinds of costs increase with a decrease in carbon cap. This indicates that stringent carbon cap will lead to an increase in the configuration cost of products.

However, the purchase cost for carbon emissions equals to 0 when carbon cap is $50.85 \mathrm{~kg} \mathrm{CO}_{2} \mathrm{e}$. This is to say, at this time, the permitted amount of carbon emissions, i.e., carbon cap, is equal to the amount produced by the configured product. Therefore, it is unnecessary to purchase addition carbon emissions from the market. As a result, the purchase cost for carbon emissions is 0 , and the total configuration cost equals to the module costs. Furthermore, when carbon cap is greater than $50.85 \mathrm{~kg} \mathrm{CO}_{2} \mathrm{e}$, for the same reason, it is unnecessary to purchase addition carbon emissions and thus, the purchase cost is 0 due to the fact that the produced carbon emissions during the configuration processes can satisfy the carbon cap.

However, the total configuration cost will be unaffected when the carbon cap is greater than $75 \mathrm{~kg} \mathrm{CO}_{2} \mathrm{e}$. The reason for this is that any configuration result satisfies the carbon cap and thus the 
constraint imposed by the carbon cap become invalid. At this time, the total configuration cost achieves its minimum and does not change with the increase in carbon cap. However, the amount of carbon emission in the product is the highest at this moment, as shown in Figure 6. When the carbon cap is less than $50.85 \mathrm{~kg} \mathrm{CO}_{2} \mathrm{e}$, the manufacturer needs to purchase extra carbon emissions to complete the configuration of customer orders since the carbon emission in any configured product will exceed the carbon cap. This will result in an increase in the purchase costs for carbon emissions and thus, the total configuration cost. However, the amount of carbon emission is the lowest at the moment, as shown in Figure 6, although it pays additional cost to purchase extra carbon quota. Therefore, it is of utmost importance to set a reasonable range for carbon cap in order to reduce both cost optimization and carbon emissions. From both Figures 5 and 6, it can be concluded that a reasonable range for carbon cap is [50.85, 75]. The concrete value to be adopted depends on the trade-off between cost reduction and carbon emission reduction.

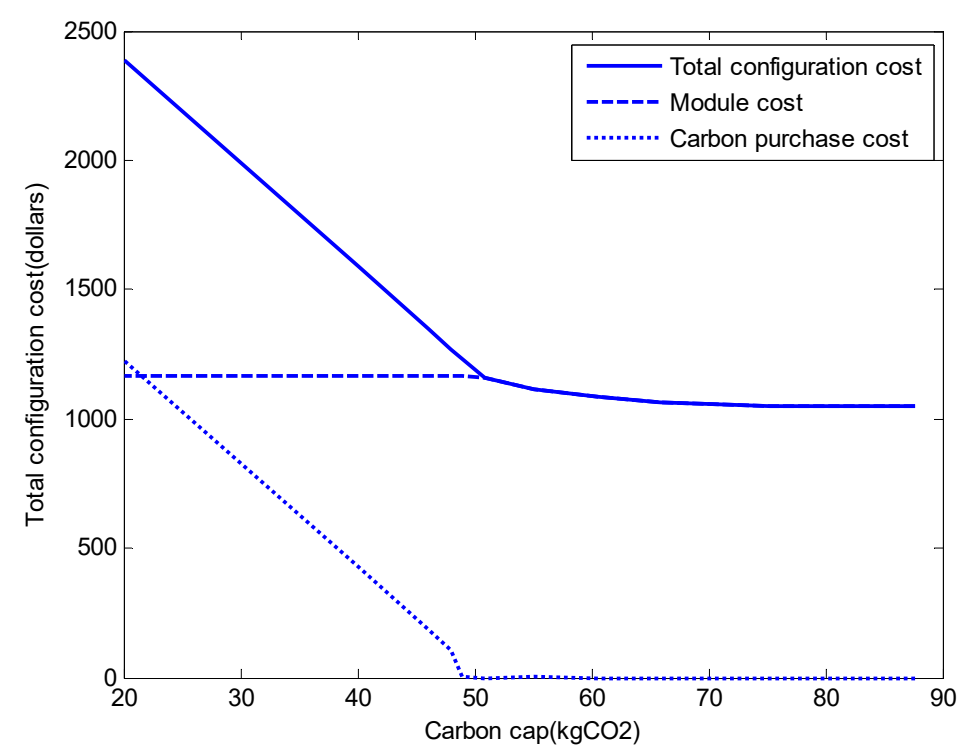

Figure 5. The effects of carbon cap on various costs.

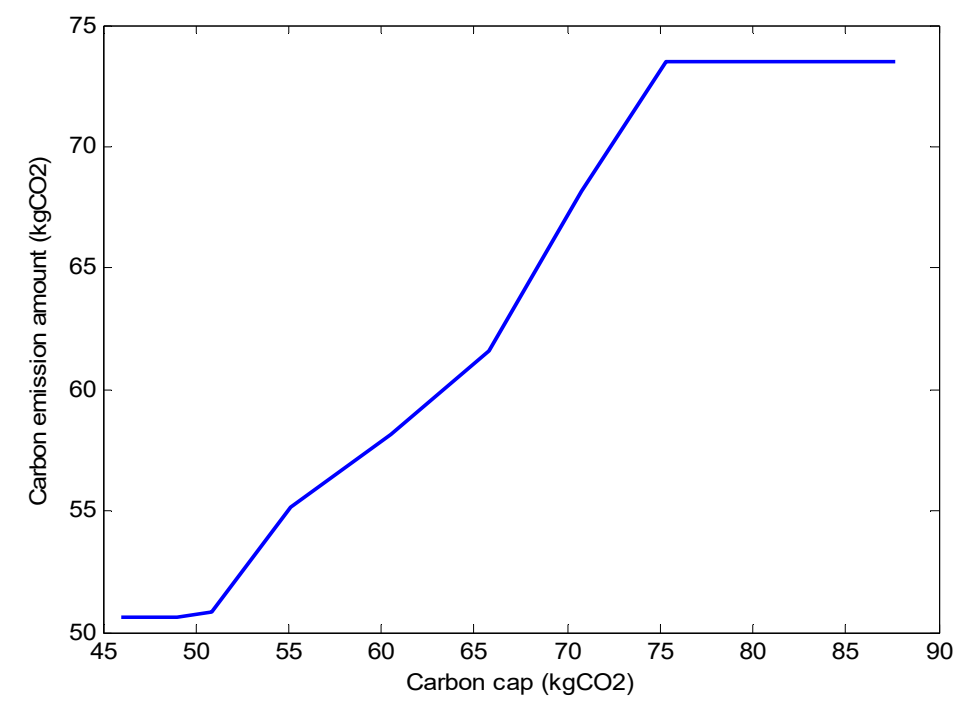

Figure 6. Carbon emissions and carbon cap under the cap-trading schema. 


\section{Conclusions}

To deal with the product configuration problem under the cap-and-trade regulation, a mixed-integer programming model is built with the objective of minimizing total configuration costs, subject to the carbon emission regulation. For different carbon allowances, optimal configuration results are obtained and configuration costs are further analyzed. The results indicate that a stringent carbon cap will lead to an increase in both total configuration cost and carbon purchase cost, but a decrease in the generated carbon emission amount. On the other hand, a loose carbon cap will result in low configuration cost and high carbon emission amount. Consequently, the value of carbon cap is a key to make a balance between total configuration cost and carbon emission amount. The reasonable range for setting the value of the carbon cap is suggested by analyzing the relationships among configuration cost, carbon emission amount and carbon cap. There are several further research directions to explore. One is to investigate the configuration problem considering both uncertain carbon trading prices and multi-sourcing suppliers for modules within a supply chain. Another interesting direction is to explore the configuration problem considering both product end-of-life strategy like remanufacturing and circularity performances and carbon cap-and-trade regulation.

Author Contributions: Conceptualization, D.Y.; methodology, D.Y.; software, J.L. and Y.-j.J.; validation; investigation, B.W. and J.L.; resources, B.W.; and J.L.; writing—original draft preparation, X.C.; writing—review and editing, D.Y.; visualization, Y.-j.J; supervision, D.Y.; project administration, D.Y.; funding acquisition, D.Y. Authorship must be limited to those who have contributed substantially to the work reported. All authors have read and agreed to the published version of the manuscript.

Funding: This research was funded by the MOE (Ministry of Education in China) Project of Humanities and Social Sciences under Grant No. 18YJA630129) and the National Natural Science Foundation of China under Grant No. 71971053, 71832001.

Conflicts of Interest: The authors declare no conflicts of interest.

\section{References}

1. Sabin, D.; Weigel, R. Product configuration Frameworks-A survey. IEEE Intell. Syst. 1998, 13, 42-49. [CrossRef]

2. Jiao, J.; Tseng, M.M. A methodology of developing product family architecture for mass customization. J. Intell. Manuf. 1999, 10, 3-20. [CrossRef]

3. Simpson, T.W. Product platform design and customization: Status and promise. Artif. Intell. Eng. Des. Anal. Manuf. 2004, 18, 3-20. [CrossRef]

4. Jiao, J.; Simpson, T.W.; Siddique, Z. Product family design and platform-based product development: A state-Of-The-Art review. J. Intell. Manuf. 2007, 18, 5-29. [CrossRef]

5. McDermott, J. R1: A Rule-Based Configurer of Computer Systems. Artif. Intell. 1982, 19, 29-88. [CrossRef]

6. Zhang, L.L. Product configuration: A review of the state-Of-The-Art and future research. Int. J. Prod. Res. 2014, 52, 6381-6398. [CrossRef]

7. Tseng, H.E.; Chang, C.C.; Chang, S.H. Applying case-Based reasoning for product configuration in mass customization environments. Expert Syst. Appl. 2005, 29, 913-925. [CrossRef]

8. Lee, H.J.; Lee, J.K. An effective customization procedure with configurable standard models. Decis. Support Syst. 2005, 41, 262-278. [CrossRef]

9. Stumptner, M.; Friedrich, G.E.; HaselBock, A. Generative constraint based configuration of large technical systems. Artif. Intell. Eng. Des. Anal. Manuf. 1998, 12, 307-320. [CrossRef]

10. Xie, H.; Henderson, P.; Kernahan, M. Modeling and Solving engineering product configuration problem by constraint satisfaction. Int. J. Prod. Res. 2005, 43, 4455-4469. [CrossRef]

11. Aldanondo, M.; Vareilles, E. Configuration for mass customization: How to extend product configuration towards requirements and process configuration. J. Intell. Manuf. 2008, 19, 2008. [CrossRef]

12. Frutos, J.D.; Santos, E.R.; Borenstein, D. Decision support system for product configuration in mass customization environments. Concurr. Eng. Res. Appl. 2004, 12, 471-478. [CrossRef] 
13. Hong, G.; Hu, L.; Xue, D.; Tu, Y.L.; Xiong, Y.L. Identification of the optimal product configuration and parameters based on individual customer requirements on performance and costs in one-Of-A-Kind production. Int. J. Prod. Res. 2008, 46, 1-30. [CrossRef]

14. Zhou, C.; Lin, Z.; Liu, C. Customer-Driven product configuration optimization for assemble-To-Order manufacturing enterprises. Int. J. Adv. Manuf. Technol. 2008, 38, 1-2. [CrossRef]

15. Li, B.; Chen, L.; Huang, Z.; Zhong, Y. Product configuration optimization using a multi-Objective genetic algorithm. Int. J. Adv. Manuf. Technol. 2006, 30, 20-29. [CrossRef]

16. Song, J.S.; Lee, K.M. Development of a low-Carbon product design system based on embedded GHG emissions. Resour. Conserv. Recycl. 2010, 54, 547-556. [CrossRef]

17. Zhang, X.F.; Zhang, S.Y.; Hu, Z.Y.; Yu, G.; Pei, C.H.; Sa, R.N. Identification of connection units with high GHG emissions for low-Carbon product structure design. J. Clean. Prod. 2012, 27, 118-125. [CrossRef]

18. Kuo, T.C. The construction of a collaborative framework in support of low carbon product design. Robot. Comput.-Integr. Manuf. 2013, 29, 174-183. [CrossRef]

19. Yi, Q.; Li, C.; Tang, Y.; Chen, X. Multi-Objective parameter optimization of CNC machining for low carbon manufacturing. J. Clean. Prod. 2015, 95, 256-264. [CrossRef]

20. Kwak, M.; Kim, H. Green profit maximization through integrated pricing and production planning for a line of new and remanufactured products. J. Clean. Prod. 2017, 142, 3454-3470. [CrossRef]

21. Loon, P.; Wassenhove, L. Assessing the economic and environmental impact of remanufacturing: A decision support tool for OEM suppliers. Int. J. Prod. Res. 2017, 56, 1-13.

22. Moon, S.K. Sustainable product family configuration based on a platform strategy. J. Eng. Des. 2017, 28, 731-764.

23. Saidani, M.; Kim, H.; Yannou, B.; Leroy, Y.; Cluzel, F. Framing Product Circularity Performance for Optimized Green Profit. In Proceedings of the International Design Engineering Technical Conferences and Computers and Information in Engineering Conference (IDETC/CIE2019), Anaheim, CA, USA, 18-21 August 2019.

24. Igarashi, K.; Yamada, T.; Gupta, S.M.; Inoue, M.; Itsubo, N. Disassembly system modeling and design with parts selection for cost, recycling and $\mathrm{CO}_{2}$ saving rates using multi criteria optimization. J. Manuf. Syst. 2016, 38, 151-164. [CrossRef]

25. Tang, D.; Wang, Q.; Ullah, I. Optimisation of product configuration in consideration of customer satisfaction and low carbon. Int. J. Prod. Res. 2017, 55, 3349-3373. [CrossRef]

26. Kwak, M.; Kim, H. Assessing product family design from an end-Of-Life perspective. Eng. Optim. 2011, 43, 233-255. [CrossRef]

27. Carl, J.; Fedor, D. Tracking global carbon revenues: A survey of carbon tax versus cap-And-Trade in the real world. Energy Policy 2016, 96, 50-77. [CrossRef]

28. Chelly, A.; Nouira, I.; Frein, Y.; Hadj-Alouane, A.B. On The consideration of carbon emissions in modelling-Based supply chain literature: The state of the art, relevant features and research gaps. Int. J. Prod. Res. 2019, 57, 4977-5004. [CrossRef]

29. Wang, C.H. Incorporating customer satisfaction into the decision-making process of product configuration: A fuzzy Kano perspective. Int. J. Prod. Res. 2013, 51, 6651-6662. [CrossRef]

30. Pitiot, P.; Monge, L.G.; Aldanondo, M.; Vareilles, E.; Gaborit, P. Optimisation of the concurrent product and process configuration: An approach to reduce computation time with an experimental evaluation. Int. J. Prod. Res. 2020, 58, 631-647. [CrossRef]

31. Jiao, Y.; Yang, Y. A product configuration approach based on online data. J. Intell. Manuf. 2019, 30, $2473-2487$. [CrossRef]

32. Zheng, P.; Xu, X.; Yu, S.; Liu, C. Personalized product configuration framework in an adaptable open architecture product platform. J. Manuf. Syst. 2017, 43, 422-435. [CrossRef]

33. Chu, P.C.; Beasley, J.E. A Genetic Algorithm for the Multidimensional Knapsack Problem. J. Heuristics 1998, 4, 63-86. [CrossRef]

(C) 2020 by the authors. Licensee MDPI, Basel, Switzerland. This article is an open access article distributed under the terms and conditions of the Creative Commons Attribution (CC BY) license (http://creativecommons.org/licenses/by/4.0/). 